\section{THE MALADIES OF CHINESE PUBLIC ADMINISTRATION*}

\author{
King W. CHOW \\ Haiyan XIAO \\ Mingyue WEN
}

\section{King W. CHOW}

Professor, School of Public Administration, Sichuan University, Chengdu, Sichuan, China Tel.: 0086-1330-820.3320

E-mail: kingwchow@163.com

\section{Haiyan XIAO}

PhD student, School of Public Administration, Sichuan University, Chengdu, Sichuan, China Associate Professor, School of Management, Hechi University, Hechi, Guangxi, China

Tel.: 0086-1587-867.2299

E-mail: missxiaohy@163.com

\section{Mingyue WEN (corresponding author)}

Postdoctoral Fellow, School of Government, Nanjing University, Nanjing, Jiangsu, China

Tel.: 0086-1318-281.2269

E-mail: mingyuewen@hotmail.com

* Acknowledgment. This project (Code \# 2016M601780) is funded by the China Postdoctoral Science Foundation.

\section{Abstract}

We conducted field research in China in 2010-2016 to diagnose the fundamental problems of Chinese public administration as a field of study (hereafter CPA). Our research question was 'What are the obstacles that impede the genuine progress of CPA?'; our study shows that CPA lacks philosophical and intellectual underpinnings to justify its existence.

Moreover, salvation is difficult as CPA has been suffering from three maladies, namely, reductionism, traditionalism, and conservatism, which together reinforce mediocrity. Furthermore, in order to become an indispensable field of study, scholars must strive to transform themselves so as to transform CPA. The implications for transformation of such practical examples as historical analysis and 'optimal governance' are discussed.

Keywords: Chinese public administration, conservatism, optimal governance, reductionism, traditionalism. 


\section{Introduction}

Public administration as a field of study (hereafter PA) focuses on the theoretical advancement of political-administrative knowledge to inform practice. In advanced economies, PA is concerned with theory development, evidence-based policy and administrative practices, and professional pedagogy. Some Western PA scholars have found the development of PA unsatisfactory, suffering from such maladies as theoretical meagerness (Fitzpatrick et al., 2011; O'Toole and Meier, 2015), insufficient philosophical and intellectual underpinnings (Durant and Rosenbloom, 2016; Neumann, 1996), methodological simplification (Perry, 2012; Spicer, 2005) and the erosion of core competence (Lynn, 2001; Rodgers and Rodgers, 2000).

In developing countries, PA primarily involves the importation of Western administrative theories and models; the validity and usability of political-administrative knowledge, however, are conditioned by contextual factors (Haque, 2010). Given the diversity and variety of political-administrative contexts in developing countries (König, 2004), the regularities of exercise of public authority, as well as the study of it, would vary. Thus, indiscriminate application of imported knowledge is bounded to be troublesome. After all, research has already documented that ' ... the recipe for prosperity has many ingredients, that their exact quantities, mix, and the sequence in which they should be introduced are not well known' (Bertucci and Alberti, 2005, p. 339).

Evidence-based policy research and the development of theoretical knowledge sensitive to the unique contextual peculiarities are therefore imperative. Thus, some development administration scholars underscore the values of such approach as 'particularism' to produce context-specific propositions (Candler, 2002). Accordingly, they research the relationship between contextual constraints and idiosyncratic practices to generate usable knowledge, such as the theoretical proposition of 'good enough governance' (Grindle, 2004). However, administrative practices in developing countries are still problematic, with inefficiency, ineffectiveness, and corruption being endemic (Barabashev and Straussman, 2007; Caulfield, 2006; Werlin, 2003). Yet, PA scholars are unable to articulate theory-based solutions and strategy-driven remedies for these problems, which is precisely the case in the People's Republic of China (PRC).

The development of PRC has been unique. It was an economically backward Marxist-Leninist state subscribed to Mao Zedong's revolutionary idealism since its establishment in 1949. It then became a politicized state after Mao launched the Great Cultural Revolution (1966-1976) to purify the state apparatus. After Mao passed away in 1976, Deng Xiaoping subsequently became the supreme leader in 1978; he placed a premium on productivity and then engineered a series of economic reforms. Under Deng's leadership, pragmatism replaced Mao's revolutionary romanticism, market mechanism and capitalism were legitimized while individualism, hedonism, and instrumentalism were unsanctioned. Consequentially, the Chinese people's motivation to optimize the market values of idle production resources was created and then reinforced by Deng's market reform policy. After joining the World Trade Organization in 2001, economic development has further speeded up in the context of globalization 
and since 2014 China has acquired the status of the world's second-largest economy by nominal GDP.

The impressive economic achievements in the past decades, however, are accompanied by such problems as epidemic corruption, outright organizational cheating, brutal abuse of human rights, and ongoing social unrests (Harwit, 2014). These problems could eventually trigger regime collapse as many political observers have predicted (Gilley, 2008; Ogden, 2014). Could Chinese PA (hereafter CPA) help to avoid regime collapse by generating theory-driven development strategies and remedies? Is CPA well developed enough to render these critical services? What is to be done and undone by CPA scholars? In order to address these questions, we conducted field research in PRC between 2010 and 2016 to diagnose the basic problems of CPA. Our specific field research question was 'What are the obstacles that impede the genuine progress of CPA?'

\section{Research methods}

To address the aforementioned research question, we used three research methods, namely, document analysis, field observation and in-depth interview. Regarding document analysis, we had reviewed relevant statutes passed by the People's Congress of China, policy statements issued by CPC, and official policy papers on management rules and regulations published by various offices of the State Council, provincial governments, and municipalities, as well as some universities' faculty management rules and regulations and promotion policy. All together these formed a basis for us to recognize the legal and official ramifications of the administrative reality and policy prescriptions governing academic behaviors. Furthermore, we had reviewed more than 300 scholarly articles (written in Chinese) on administrative issues released in the past decade and more than one thousand official newspaper reports published from 1978 to January 2016, particularly reports published in the People's Daily, the official newspaper of the Communist Party. These articles and reports provided a knowledge base to supplement the interview data and to triangulate field observation findings.

Regarding field observation, the first author was an American trained political scientist teaching at universities in USA and Hong Kong since 1984 and had conducted field research in various provinces in PRC as early as 1983 (Chow, 1988). After joining a leading university in southwestern China to teach MPA courses in 2004, he was able to establish networks with government officials and PA scholars throughout PRC, as most Chinese MPA students were state cadres with work experience and a social network. As a result, he could conduct field observation and participated in major local political events, such as the provincial Plenary Session of the Communist Party of China (CPC). His networking with senior public administration scholars in PRC made it possible for him to pursue field studies in Chengdu, Beijing, Guangzhou and Shanghai. In addition, as a senior professor, he had also participated in decision-making events in his university and the provincial and municipal governments, observing how senior administrative cadres reasoned and behaved. Basing his research on field 
observation, he summarized various observational findings about the regularities of administrative decision-making and cause-and-effect mechanisms, and then discussed with CPA scholars in major universities those findings through e-mails, faceto-face conversation, and conferencing. He also made observations of the teaching and professional consultation of CPA scholars to generate a better understanding of how CPA scholars behave, reason, calculate and strategize in their teaching, research and community servicing. The other two authors joined the same pursuit in Guangxi and Jiangsu since 2015 and their findings are in congruence with the first author's.

Regarding the third research method (the field interview), elite interview in Marxist-Leninist states is indispensable as governmental information is neither publicized fully nor in a timely manner. The authors had therefore conducted 720 in-depth interviews between 1983 and 2017, involving 835 state cadres and academicians in Baotou (Inner Mongolia), Beijing, Chengdu, Dalian, Guangzhou, Guiyang, Hechi (Guangxi), Lanzhou, Nanjing, Shanghai, Shenzhen, Suzhou, Taiyuan, Wuhan, Xi' an, Zhengzhou and Zhuhai, covering most major cities in China. The authors consider that the essence of all public administrative phenomena is 'responsible purposive authority application' (RPAA) and that RPAA is a function of various forces (i.e., socio-cultural, institutional, political, organizational, technological, executive, cognitive, and human, which can be linked up to construct an acronym, 'SIPOTECH'), which act in concert to generate interactive and configurative contextual effects on the general, specific and peculiar types of RPAA. It is therefore imperative to use interviewing to generate all available data and evidence about the SIPOTECH dynamics of RPAA. Thus, semi-structured interview, lasting from 30 minutes to three hours, was used to collect as much information and insights as possible from the interviewees. Furthermore, instead of journalistically focusing on 'what' had happened 'where', 'when' and for 'what' reasons, interviewees were asked to reflect on some critical administrative events to explore the underlying behavioral logics and causal mechanisms of SIPOTECH forces. To ensure that the interviewing findings are valid, the authors had used information and evidence collected from document analysis and field observation to triangulate. When discrepancy was observed, more interviews were then conducted to clarify.

Based on the three research methods, findings about the obstacles that impede the genuine progress of CPA are presented below.

\section{CPA under criticism}

As part of the reform efforts to modernize PRC, CPA was institutionalized in the 1980s (Chow, 1991). Our field observation and interviews have revealed that CPA scholars are generally pleased with the institutional development of CPA in the past three decades, with hundreds of universities offering B.A., M.A., MPA, and Ph.D. programs in public administration and policy studies. However, such American-trained CPA scholars as Ma (2006) had voiced critiques, targeting such problems as reliance on the importation of foreign theories, lacking methodological rigor and insufficient 
concern for deep level administrative problems. Others (Lu and Chow, 2008; Cheng and $\mathrm{Lu}, 2009$ ) were displeased with CPA efforts being primarily directed at justifying institutional and administrative reforms from the CPC perspective; similar critiques still surface in the second decade of the century (see Zhang and Bai, 2015).

$\mathrm{Lu}$ and Chow (2008) had conducted a content analysis of CPA journal articles, and found that CPA had suffered from various research deficiencies, for example, scholars' tendency to pursue a-theoretical studies and researchers' lacking the capacity to use sophisticated methodology to develop theories. As a result, CPA could hardly be a source of indigenous theories to inform political-administrative practice. Cheng and $\mathrm{Lu}(2009)$ had reported similar findings in their content analysis of journal articles and further underscored that defective CPA research had produced non-usable knowledge to help CPC to refine its governance policy and practices, and thus could be considered a prime factor that contributed to CPC's diminishing legitimacy.

A recent research (Li and Zhou, 2018) has documented that atomization of interest has become an objectified reality in China since the 1960s and, as such, most Chinese, inclusive of CPC members, have been concerned with safeguarding or optimizing personal interests. Atomization of interest contradicts the basic values of socialism and is dismantling CPC as a revolutionary vanguard party. In other words, CPC's governance legitimacy is on the verge of breaking down. Western-style democratization as forecasted by China watchers (Gilley, 2008) may soon become a reality. Yet, Western style democratization that takes place in a context of atomization of interest along with defective rule-of-law policy may result in gaming and realpolitik and in turn political instability or even chaos (Wen, 2018).

In view of the political analysis above, one would note that not only CPC's regime continuity is at stake, but that the well-beings of the 1.38-billion Chinese is also under threat. CPA, however, is hardly responsive or proactive. Our recent literature review has documented that the various research problems of CPA as criticized years ago (Cheng and Lu, 2009; Lu and Chow 2008; Ma, 2006) have remained intact in the 2010s. Furthermore, CPA scholars have failed to either entertain the likelihood of regime collapse or strive to advance new political-administrative theories to guide the strategic development of PRC to avoid political chaos. Obviously, CPA does not have sufficient philosophical and intellectual underpinnings to justify its existence. Salvation, however, is difficult.

Our field observation and interviews have revealed that CPA has been suffering from three maladies, namely, reductionism, traditionalism, and conservatism, which together reinforce mediocrity. If untreated, these maladies would make CPA's redemption impossible, preventing its political-administrative theoretical breakthrough that PRC badly needs.

\section{The malady of reductionism}

The malady of reductionism has conditioned CPA scholars' preference for narrow analytic perspectives and research foci. Reductionism has prevailed in China for 
more than six decades. In brief, popularized in PRC in the 1950s, it was the Soviet model of reductionism for specialization in industrialization and in higher education and research. Specialization in manufacturing may generate greater marginal benefits but in teaching and research, however, such an approach stifles holistic thinking.

Under the influence of the Soviet model of reductionism, CPA scholars have adopted the reductive approach to analyze specific issues through narrow perspectives. Therefore, they focus merely on the advancement of such specialized technical knowledge as the design of performance assessment instrument for such specific administrative job as performance management. Overlooked is the fact that all political-administrative phenomena are interrelated and thus could only be comprehended through a holistic perspective. For example, the enhancement of performance management in developing countries would necessitate the analysis of the configuration of socio-economic forces and changing political preferences that together mold the here-and-now and future governmental performance (Zhou and Wan, 2009). Thus, narrowly focusing on assessment instruments and specific performance could hardly yield usable knowledge to optimize systemic performance. Conditioned by the malady of reductionism, CPA scholars just could not develop the needed holistic thinking. Unfortunately, their MPA teaching also affect young government officials, who could hardly become holistic thinkers to tackle managerial and policy problems through a holistic perspective.

Anti-corruption is also a case in point; CPA scholars' have produced massive scale reports about various corrupt practices. These descriptive reports, however, are insufficient for articulating effective remedies. In contrast, with a broader perspective, CPA scholars would recognize that the formulation of an effective solution must take both individual- and group-level factors into consideration. At the individual-level, egoistic state cadres as power wielders are prone to abuse public authority when accountability is absent due to their secured political protection from corrupt syndicates. At the group-level, corrupt syndicates providing reciprocal protection against disciplinary investigation have already been well developed in the past three decades. Furthermore, the syndicates have prospered because, after the Tiananmen Square protests of 1989, the CPC leadership has placed a premium on political stability. As a result, anti-corruption confrontation at the individual-level, which could intensify political conflicts at the group-level have been rare. The aforementioned analysis of corruption could become a basis for making an effective anti-corruption policy advice that calls for strong leadership willing to institutionalize efforts to penalize corrupt power wielders and to dismantle corrupt syndicates at the risk of political instability. CPA scholars could have articulated such a policy advice if they would have focused on the root causes of corruption through a holistic perspective.

The example above also shows that effective theorizing and problem-solving must be based on a holistic understanding of how factors of historical development, political mandate, political incentives, networking and behavioral tendencies act in concert. Unfortunately, CPA scholars lack this holistic understanding, which is an 
unavoidable consequence of applying the reductive approach. When scholars fail to equip themselves with the essential holistic perspective and understanding, their research findings and pedagogy are inescapably deficient. As such, the instrumental value of CPA scholarship is inevitably limited.

\section{The malady of traditionalism}

Regarding traditionalism, CPA scholars' adherence to conventional practices has encouraged them to cumulate knowledge with the use of mainstream approaches, conceptual frameworks, and research methods. The problem of the popular practice of information accumulation is revealing. In social scientific research in the West, information is essential to the scholarly pursuits of scientific realism, scientific empirical foundationalism, scientific instrumentalism, and social constructionism (Chow and Luo, 2016). In the case of CPA, however, scholars under the influence of the malady of reductionism have unwisely focused on information per se, and thus are trapped in an 'information-rich but interpretation-poor paradox'- that is, the more one knows, the less one understands.

Generally speaking, the more isolated and stable a political-administrative issue (such as political unrest triggered by state cadres' embezzlement of poverty-relief fund) is, the more useful information would be for resolving the issue; yet, the more complex, interrelated issues (such as inequality-induced poverty dynamics) are, the greater the reliance on genuine understanding (of fundamental physiological, psychological, and socio-economic causes) would be. In other words, information has a place but must be kept in place.

Yet, in CPA, accumulation of information about administrative problems and reform implementation within and outside PRC has become an ends rather than a means. As a result, CPA scholars often got buried in the rich mine of descriptive data, forgetting the differences between knowing and understanding. For example, CPA scholars had focused on the New Public Management (NPM) movement in the 1990s, they produced plentiful reports about NPM practices and experiences in the West and then advocated NPM reform in PRC. Satisfied with their systematic presentation of descriptive information, they never bothered to scholarly analyze the prerequisite of NPM's reform measures - the quantifiability of government outputs and results. In recent years, CPA scholars have reported, in massive scale, the model of good governance advocated in advanced economies but none made any attempt to analyze the necessary conditions for effectuating good governance in the West and in PRC.

In the 2010s, CPA scholars are still busy in producing here-and-now descriptive information, thus merely generating low quality publication. Unfortunately, such a mediocre practice has in fact been reinforced by the current academic incentive system, which rewards academicians based on the quantity of their publication, rather than quality. As their commitment to information accumulation is reinforced by the superficial scholarship assessment system, their scholarly urge to research on the prime causes and changing regularities of fundamental political-administrative prob- 
lems is inevitably weak. Genuine advancement of theoretical knowledge is therefore rare. Consequentially, the theory-based articulation of solutions to such fundamental problems as state cadres' atomization of interests (Li and Zhou, 2018) and citizens' rejection of regime values (Harwit, 2014), which together could eventually lead to regime collapse, is absent.

\section{The malady of conservatism}

The third malady is conservatism. In brief, the aforementioned popularized preference for reductive analysis and concern for information accumulation have conditioned CPA scholars into risk-aversive researchers, opposing radical changes in their research and pedagogical pursuits. They tend to avoid critical or creative studies, which are too scholarly taxing and politically dangerous and which produce research outputs that are often not publishable due to the conservative stance of journal editors and publishers. They would rather pursue descriptive, normative, and non-analytical research - that is, insignificant research. The inevitable consequence is their failure to enhance strategic insights and innovative ideas essential to the overhauling of PRC's political-administrative system design and practices.

Consider the CPC's cadre selection policy of 'virtue over competence': CPC has stressed that state cadres must be virtuous and competent, but when competence is on a par, those who are 'more virtuous' are to be promoted. Virtue, however, could be subjectively assessed. Indeed, our field interviews have revealed that, in the current pragmatic-rational context, bribery and social networking are sufficient conditions for immoral cadres to get promoted. Whereas this established policy has resulted in the appointment of corrupt and/or incompetent cadres at massive scale, no CPA scholars have ever challenged the validity of this defective policy due to their conservative stance. They merely follow CPC guidelines and prescriptions to delineate in detail what constitute virtuous behaviors. As a result, strategic human development theories and assessment inventories essential to the selecting, training, and grooming of state cadres who are committed to perform competently to realize socialist values are absent from the literature. The inevitable consequences are ineffective cadre differentiation and, in turn, the appointment of corrupt cadres in disguise.

Due to conservatism, CPA scholars accept the political-administrative reality as it is, considering it to be static and beyond manipulation. By accepting the world as given, their teaching and research are conducted within a post-institutional context (i.e., the systems and structures are given), rather than pre-institutional (i.e., the systems and structures, as well as laws and policies, are to be created); inevitably, creative, proactive, and strategic analyses are rare in CPA.

\section{Foreign-trained CPA scholars in infirmity}

It should be noted that in the past decade more CPA scholars have received their doctoral education in developed countries, particularly in the United States of America. Recently, many top CPA programs have even adopted the policy of recruiting 
only scholars with doctoral degree conferred by world class universities. Comparing with locally trained CPA scholars, they are supposed to be untraditional and non-conservative in terms of their Westernized worldview, and have interdisciplinary knowledge, methodological sophistication, and professional commitment. In essence, however, their mind-frames and approaches are still remarkably similar to the locally trained scholars'. These scholars have merely pursued their teaching, research, and community service in another form of traditionalism, reductionism, and conservatism.

For example, some American-trained CPA scholars consider empirical analysis a scared practice and thus focus on collection and analysis of quantitative data to reveal regularities of political-administrative phenomena. Application of this quantitative analytic approach is untraditional in CPA. Yet, such a practice is in fact conventional, as it has been well established in developed countries for many decades. Further, these American-trained CPA scholars have overlooked an important guideline that quantitative analysis is indispensable only in addressing questions of frequency and magnitude (Giorgi, 2005) that are circumscribed by a political-administrative context characterized by ecological stability, political gradualism, and policy incrementalism.

In developing countries, changes are frequent and could be drastic. As a result, the here-and-now empirical data analysis could generate merely propositions about regularities that are valid in a short time-span. Such popularized quantitative analytic practices in CPA as public opinion polls and cost-benefit evaluation of public policies are illustrative - the findings generated could become invalid overnight as soon as CPC introduces new interpretation of policy intent or mandates! Foreign-trained CPA scholars' conventional application of the quantitative analytic approach without noting contextual dynamics and their implications for research reflects that they are merely traditional technicians, rather than strategic thinkers.

The malady of traditionalism is further aggravated by an inherent defect of foreign-trained CPA scholars' empirical analysis, which focuses narrowly on a specific set of data about a specific phenomenon or causal relationship in a particular time-framework. The causes of problems in developing countries are complex, interrelated, and dynamic. In PRC, historical events, political institutional arrangements, substantive policies, sociological norms, social practices, power wielders' instrumental-rational calculation, stakeholders' deviant psychological tendencies, etc. have acted in concert to dynamically influence macro- and micro-level political-administrative behaviors. The reductive approach employed by the foreign-trained CPA scholars could only help generate empirical findings about individual trees rather than the forest and about leaves rather than roots. Theories and policy solutions formulated in this way are inevitably invalid and ineffective.

These scholars also suffer from the malady of conservatism. They basically apply popular research methods learned during their doctoral training, refusing to take risks in learning and/or using unconventional methods, such as meta-analysis, computer simulation, human-assisted simulation and proactive-strategic analysis. Fur- 
thermore, some of them conservatively accept the Marxist-Leninist PRC as it is, while others consider Western-style democratization desirable and inevitable. Regardless of the rationales, their mindset of accepting current institutional structures and policies or advocating democratization is path-dependent. The either-or approach suffocates their imagination and creativity. Thus, pre-institutional studies and proactive research are never on their research agenda.

For example, in the past two years, the CPC propaganda machinery has openly criticized the popular practice of university faculty members' expressing in the classroom their disapproval of CPC governance and their whole-hearted endorsement of Western democratic practices. Eventually, the Education Ministry has issued instructions to university administrators to effectuate political monitoring. As a result, CPA scholars who accept the system as it is continue their research on managerial issues of inefficiency and ineffectiveness; those who prefer Western-style democratization preach the values of good governance and call for incremental reforms that enhance institutional redesign for good governance. None of them consider the pitfalls of the 'one-size-fits-all' recommendation (Vigoda-Gadot, Cohen and Tsfati, 2016). Inevitably they disregard the needs to realize 'good enough governance' (Grindle, 2004) or to creatively devise a new form of governance that could supersede good governance.

\section{Discussion}

$\mathrm{CPA}$ as a field of study that analyzes the regularity and causality of blending political, administrative and economic powers together for the realization of modernization of PRC could be a generator of theoretical knowledge and strategic insights for solving current and foreseeable political-administrative problems. The maladies of reductionism, traditionalism, and conservatism, however, have made the CPA pursuit difficult, if not impossible. Be they locally trained or foreign-trained, CPA scholars are suffering from these maladies, thus making mediocrity a hallmark of CPA.

Furthermore, our field observation and interviews have shown that these maladies not only limit the instrumental value of CPA scholars' pursuit, but also help to condition their mindset, blinding their perception, ossifying their thought, limiting their cognitive capacity and suffocating imagination. Inevitably, they could neither creatively produce usable knowledge for problem-solving nor systematically articulate indigenous political-administrative theories for guiding and prescribing the strategic development of PRC. Our content analysis of articles published in leading CPA journals over the past few years has indeed indicated a great majority of Chinese scholars are still publishing the 'known' or suggesting the quick-fix or 'wound plaster' solutions, rather than new ideas and insights or genuinely devised innovative solutions. As the younger generation follows the same path, a vicious cycle would emerge. This is an undesirable destiny, which makes CPA a dispensable field of study.

Obviously, CPA must be transformed in order to enhance its philosophical and intellectual underpinnings. To break away from the current developmental trends, scholars need to make great efforts to transform CPA by eliminating reductionism, 
traditionalism, and conservatism. Scholars have to strive to transform themselves in order to transform CPA. The first step to take is to foster their own commitment to pursuing meaningful research that has theoretical and instrumental values. As a necessary condition for transformation, their commitment could help them identify valuable research problems. Committed scholars would no longer pursue descriptive studies of the importation of Western administrative theories and models, they would instead focus on the deeper level regularities of effectuation of optimal political-administrative performance in China's political-cultural context. For example, they would consider conducting historical analysis to explore those important but overlooked regularities. Historical analysis is an unconventional practice in PA generally (Raadschelders, 2010) and in CPA particularly (Chow and Luo, 2016), but it could be a source of valuable insights as its application could yield findings essential to the development of CPA's core competence, which in turn justifies CPA's existence.

Indeed, such CPA scholars as Chow and Luo (2016) had conducted a fruitful historical analysis. They found that CPC could establish PRC all because of its unique value system, which was widely endorsed by the Chinese people from all walks of life. In appearance, the values propagandized were freedom, equality and equity. But Chow and Luo's (2016) detailed document analysis reveals that there were three deeper level core values being advocated and realized by CPC between 1930s and 1950s. They were 'genuine respects for others', 'willingness to help the needed', and 'co-development for co-prosperity'. Driven by these values, the CPC leadership did not follow the Marxist-Leninist tradition of proletariat revolution. Instead, CPC committed itself to the liberation of all the people suffering from all kinds and forms of exploitation and suppression, and then strived to search for innovative means and ways to establish a new China that cherished and materialized the three deeper level core values.

Moreover, CPC members' internalization of the values of respect, altruism, and co-development (hereafter the RAC values) has fostered their urge to contribute to the institutionalization of CPC's model of 'optimal governance'. This model prescribed that the sole function of governance was to apply public authority to shape the political, social and economic contexts in order to create favorable conditions that helped to promote people to mutually grow and develop. In the process, state cadres and citizens who had a strong sense of social responsibility fostered by the RAC values would seek to advance practical knowledge and develop new skills and techniques to optimize their job performance and in turn their contribution to society. As a result, even illiterate slaves were nourished into medical doctors and military commanders, while poor peasants and unskilled workers became competent professionals. These growing and developing people then acted in concert to create miracles - for example, CPC could turn its 50,000 Red Army (in 1937) into a 3-million-plus People's Liberation Army and then managed to militarily defeat the American-equipped 4-million-plus Nationalist troops in the 1947-49 civil war.

Furthermore, Chow and Luo's (2016) document analysis reveals that such a de- 
sirable model of 'optimal governance' was in fact based on the ancient Chinese political-cultural values of Confucianism, Taoism, Legalism, and Mohism, rather than Marxist-Leninism. The obvious implication is that each nation-state may prosper if their political-administrative leadership could identify the recipe for prosperity. The illustrative case above shows that idiosyncratic cultural value and political philosophy are the required ingredients of the recipe. In other words, the advancement of culture-specific political-administrative theories and models is indispensable to country-specific optimal development.

As such, the salvation of CPA is feasible if scholars place their research foci on the deeper levels of the optimal political-administrative performance that were explicated in CPC's heydays of governance and reform in the 1930s and 1950s. Most likely, their future research may yield valuable findings about the regularity and causality of effective 'optimal governance'. These findings could then serve as a basis for articulating the blueprint for transforming PRC in the $21^{\text {st }}$ Century. In addition, comparative studies of 'optimal governance' by interested PA scholars may also yield practical findings essential to the engineering of the transformation of other developing countries.

\section{Concluding remarks}

All in all, CPA scholars must treat the maladies of reductionism, traditionalism, and conservatism. Only then can they strive to pursue meaningful research to generate theories to effectively inform political-administrative reform and strategic development. The overlooked model of success known as 'optimal governance' must be rediscovered and studied. The theoretical knowledge thus generated could become the backbone of cultural-specific blueprints for enhancing a new social reality characterized by the elimination of all kinds and forms of exploitation and suppression and by Chinese people's sustainable growth and development for prosperity.

Scholars could then salvage the philosophical and intellectual underpinnings of $\mathrm{CPA}$, referring to the purposive application of public authority prescribed by administrative responsibility. It goes without saying that the transformative experience of CPA could also have spillover effects for other developing countries' PA scholars who seek to enhance or transform their PA and political-administrative system to better serve their fellow citizens and motherland.

\section{References:}

1. Barabashev, A. and Straussman, J.D., 'Public Service Reform in Russia, 1991-2006', 2007, Public Administration Review, vol. 67, no. 3, pp. 373-382.

2. Bertucci, G. and Alberti, A., 'The United Nations Programme in Public Administration: Reinventing Itself to Help Reinvent Public Administration', 2005, International Review of Administrative Sciences, vol. 71, no. 2, pp. 337-353.

3. Candler, G.G., 'Particularism versus Universalism in the Brazilian Public Administration Literature', 2002, Public Administration Review, vol. 62, no. 3, pp. 298-306.

4. Caulfield, J.L., 'Local Government Reform in China: A Rational Actor Perspective', 
2006, International Review of Administrative Sciences, vol. 72, no. 2, pp. 253-267.

5. Cheng, J.Y.S. and Lu, L.Q., 'Public Administration Research Issues in China: Evidence from Content Analysis of Leading Chinese Public Administration Journals', 2009, Issues and Studies, vol. 45, no. 1, pp. 203-241.

6. Chow, K.W., 'The Management of Chinese Cadre Resources: The Politics of Performance Appraisal (1949-1984)', 1988, International Review of Administrative Sciences, vol. 54, no. 3, pp. 359-378.

7. Chow, K.W. and Luo, S., 'On the Necessary Regression of the Value of Mao Zedong Thinking as a Methodology', 2016, Innovation, vol. 10, no. 1, pp. 23-39.

8. Chow, K.W., 'Public Administration as an Academic Discipline in China', in Farazmand, A. (ed.), Handbook of Comparative and Development Administration, New York: Marcel Dekker, 1991, pp. 409-420.

9. Durant, R.F. and Rosenbloom, D.H., 'The Hollowing of American Public Administration', 2016, The American Review of Public Administration, vol. 47, no. 7, pp. 719-736.

10. Fitzpatrick, J., Goggin, M., Heikkila, T., Klingner, D., Machado, J. and Martell, C., 'A New Look at Comparative Public Administration: Trends in Research and an Agenda for the Future', 2011, Public Administration Review, vol. 71, no. 6, pp. 821-830.

11. Gilley, B., 'Legitimacy and Institutional Change: The Case of China', 2008, Comparative Political Studies, vol. 41, no. 3, pp. 259-284.

12. Giorgi, A., 'Remaining Challenges for Humanistic Psychology', 2005, Journal of Humanistic Psychology, vol. 45, no. 2, pp. 204-216.

13. Grindle, M.S., 'Good Enough Governance: Poverty Reduction and Reform in Developing Countries', 2004, Governance, vol. 17, no. 4, pp. 525-548.

14. Haque, M.S., 'Rethinking Development Administration and Remembering Fred W. Riggs', 2010, International Review of Administrative Sciences, vol. 76, no. 4, pp. 767-773.

15. Harwit, E., 'The Rise and Influence of Weibo (Microblogs) in China', 2014, Asian Survey, vol. 54, no. 6, pp. 1059-1087.

16. König, K., 'On the Typology of Administration', 2004, International Review of Administrative Sciences, vol. 69, no. 4, pp. 449-462.

17. Li, Y.N. and Zhou, J.W., 'In Search of a Rationalized Chinese Administrative State', 2018, Public Organization Review, vol. 18, no. 1, pp. 1-19.

18. Lu, L.Q. and Chow, K.W., 'Monitoring the Growth of Chinese Public Administration Knowledge: Evidence from Chinese Public Administration Journals', 2008, Chinese Public Administration Review, vol. 5, no. 1/2, pp. 6-26.

19. Lynn, L.E.Jr., 'The Myth of the Bureaucratic Paradigm: What Traditional Public Administration Really Stood For', 2001, Public Administration Review, vol. 61, no. 2, pp. 144-160.

20. Ma, J., 'Reflections on Chinese Public Administration Research: The Courage of Facing Problems', 2006, Zhongshan University Journal, vol. 5, pp. 73-76.

21. Neumann, F.X., 'What Makes Public Administration a Science? Or, Are Its 'Big Questions' Really Big?', 1996, Public Administration Review, vol. 56, no. 5, pp. 409-415.

22. O'Toole, L.J.Jr. and Meier, K.J., 'Public Management, Context, and Performance: In Quest of a More General Theory', 2015, Journal of Public Administration Research and Theory, vol. 25, no. 1, pp. 237-256.

23. Ogden, S., 'Will China Democratize?', 2014, The China Quarterly, vol. 219, no. 3, pp. 
864-865.

24. Perry, J.L., 'How Can We Improve Our Science to Generate More Usable Knowledge for Public Professionals?', 2012, Public Administration Review, vol. 72, no. 4, pp. 479-482.

25. Raadschelders, J.C.N., 'Is American Public Administration Detached from Historical Context? On the Nature of Time and the Need to Understand It in Government and Its Study', 2010, American Review of Public Administration, vol. 40, no. 3, pp. 235-260.

26. Rodgers, R. and Rodgers, N., 'Defining the Boundaries of Public Administration: Undisciplined Mongrels versus Disciplined Purists', 2000, Public Administration Review, vol. 60, no. 5, pp. 435-445.

27. Spicer, M.W., ‘Determinism, Social Science, and Public Administration: Lessons from Isaiah Berlin', 2005, American Review of Public Administration, vol. 35, no. 3, pp. 256-259.

28. Vigoda-Gadot, E., Cohen, N. and Tsfati, Y., 'Reforming the Nations: A Global Study of the Need for Future Managerial Reforms in Public Administration', 2016, International Review of Administrative Sciences, [Online] available at http://journals.sagepub.com/doi/ full/10.1177/0020852316652225, accessed on March 22, 2018.

29. Wen, M.Y., 'The Dynamics of Sustainable Regime Continuity of China', 2018, Chinese Studies, vol. 7, no. 1, pp. 59-71.

30. Werlin, H.H., 'Poor Nations, Rich Nations: A Theory of Governance', 2003, Public Administration Review, vol. 63, no. 3, pp. 329-342.

31. Zhang, Z.S. and Bai, B., 'The Identity Crisis and Development Path of Public Administration from the Perspective of Paradigmatic Analysis', 2015, Journal of the National College of Public Administration, vol. 30, no. 6, pp. 45-50.

32. Zhou, J.W. and Wan, S.J., 'On the Three Non-rational Logics of Public Sector Performance Management', 2009, Seeker, vol. 28, no. 11, pp. 52-54. 